\title{
Journal of Science and Engineering
}

\section{Pengaruh Debit Dan Head Terhadap Daya Mikro Hidro Pada Instalasi PENgolahan AIR (IPa) Papaloang Pulau Bacan}

Try Suyono ${ }^{a^{*}}$, Lita A. Latiefa, Kifli Umara, Fitra Putra Siko ${ }^{a}$

aUniversitas Khairun, Ternate, Indonesia
Article history

Received

9 Januari 2018

Received in revised form

5 Maret 2018

Accepted

5 Mei 2018

*Corresponding author trysuyono@unkhair.ac.id

\section{Graphical abstract}

\begin{abstract}
Sustainable water resources management system is a water resources management system that is designed and managed and fully contributes to the community (social and economic) for present and in the future, while maintaining the sustainability of its ecological aspects. This research was under taken by direct observation in the field. Then the data obtained from the field is processed using a computer program. This research activity was carried out in Wasile Timur Village, East Halmahera Regency, North Maluku Province. The results of this study indicate that the diameter of the pipe used is diameter $300 \mathrm{~mm}, 250 \mathrm{~mm}, 200 \mathrm{~mm}, 150 \mathrm{~mm}, 100 \mathrm{~mm}$, and $63 \mathrm{~mm}$. Based on the variation of the pipe, the maximum pressure is $49.37 \mathrm{~m}$ or equal to 4.937 bar while the minimum pressure is $26.39 \mathrm{~m}$ or equal to $2.639 \mathrm{bar}$. As for, the pressure from the results of the analysis meets the distribution network planning criteria, namely a maximum of $9.0-12.4$ bar and a minimum of $0.5-1.0$ bar. Maximum flow speed of $0.60 \mathrm{~m} / \mathrm{s}$ and minimum speed of $0.30 \mathrm{~m}$ / sec flow velocity. Analysis results is showed the planning criteria which according to the provisions is a maximum of $2.5 \mathrm{~m} / \mathrm{sec}$ and a minimum of $0.25 \mathrm{~m} / \mathrm{sec}$.
\end{abstract}

Keywords: Power, Debit, Efficiency, Head, Micro Hydro

\section{Abstrak}

Sumber daya air yang ada perlu dikelola secara berkelanjutan.Sistem pengelolaan sumberdaya air berkelanjutan sustainable water resourses management system merupakan sistem pengelolaan sumber daya air yang didesain dan dikelola serta berkontribusi penuh terhadap tujuan masyarakat (sosial dan ekonomi) saat ini dan masa yang akan datang, dengan tetap mempertahankan kelestarian aspek ekologisnya. Penelitian ini dilaksanakan dengan cara peninjauang langsung di lapangan. Kemudian data yang diperoleh dari lapangan di olah dengan menggunakan program komputer. Kegiatan penelitian ini dilaksanakan di Kecamatan Wasile Timur Kabupaten Halmahera Timur Provinsi Maluku Utara. Hasil penelitian ini menunjukkan bahwa Diameter pipa yang digunakan yaitu diameter $300 \mathrm{~mm}, 250 \mathrm{~mm}, 200 \mathrm{~mm}, 150 \mathrm{~mm}, 100 \mathrm{~mm}$, dan $63 \mathrm{~mm}$. Dari variasi Pipa tersebut didapat Tekanan Maksimum 49,37 m atau sama dengan 4,937 Bar sedangkan Tekanan minimum sebesar 26,39 m atau sama dengan 2,639 bar. Tekanan dari hasil analisis memenuhi kriteria perencanaan jaringan distribusi yaitu maksimum 9,0-12,4 bar dan minimum 0,5 - 1,0 bar. Kecepatan aliran Maksimum sebesar 0,60 m/det dan kecepatan minimum sebesar $0,30 \mathrm{~m} /$ det kecepatan aliran pada hasil analisa memenuhi kriteria perencanaan dimana menurut ketentuan yaitu maksimum $2,5 \mathrm{~m} /$ det dan minimum sebesar $0,25 \mathrm{~m} /$ det.

Kata kunci: Daya, Debit, Efisiensi, Head, Mikro Hidro

(C) 2018 Penerbit Fakultas Teknik Unkhair. All rights reserved 


\subsection{INTRODUCTION}

Sistem Penyediaan Air Minum (SPAM) yang dibangun kebanyakan adalah sistem gravitasi dengan debit air antara $5 \mathrm{~L} / \operatorname{det}(0,05 \mathrm{~m} 3 /$ det $)$ sampai $100 \mathrm{~L} / \operatorname{det}(0,1 \mathrm{~m} 3 /$ det $)$ dengan beda tinggi (head) antara 25 sampai 100 meter, serta panjang pipa transmisi atau pipa pesat antara 700 meter sampai 12000 meter. (DITPAM PU, 2015) Dari gambaran kondisi di atas maka ada potensi pemanfaatan sisa tekan air dari bendungan (intake) ke Instalasi Pengolahan Air (IPA) untuk menggerakkan Pembangkit Listrik Tenaga Mikro Hidro (MIKRO HIDRO) sebagai sumber energi listrik untuk keperluan IPA dan sekitarnya. Untuk itu perlu dilakukan analisa hidrolis pada pipa transmisi untuk mengetahui sisa tekan air atau head sebenarnya setelah melewati pipa transmisi pada jarak tertentu.

Instalasi Pengolahan Air (IPA) Kapasitas 20-30 L/det pada Sistem Penyediaan Air Minum Ibu Kota Kecamatan (SPAM IKK) Bacan, Kabupaten Halmahera Selatan, Propinsi Maluku Utara, memiliki lokasi yang cenderung jauh dari pemukiman dan jangkauan instalasi listrik dari PLN, sehingga dibangun MIKRO HIDRO sebagai sumber energi listrik, terutama untuk sistem pompa kimia dan penerangan. Pembangkit Listrik Tenaga Mikro Hidro (MIKRO HIDRO) yang terdapat pada lokasi SPAM IKK Bacan, memiliki jarak dari intake dengan lokasi IPA yang cukup jauh yaitu 1200 meter dengan beda tinggi (head) 70 meter, namun belum ada kajian mendalam tentang pengaruh debit terhadap daya keluaran pada mikro hidro.

\subsection{METODOLOGI}

\subsection{Tempat Pelaksanaan Penelitian}

Lokasi penelitian dilaksanakan di Instalasi Pengolahan Air (IPA) pada Sumber Penyediaan Air Minum Ibu Kota Kecamatan (SPAM IKK) Bacan, Kabupaten Halmahera Selatan, Propinsi Maluku Utara.

\subsection{Alat}

Alat-alat yang digunakan pada penelitian ini, diantaranya :

1. Mikro hidro

Mikro hidro memiliki 3 komponen utama, yaitu :

1. Air sebagai sumber energI

2. Turbin yang digunakan pada penelitian ini adalah Turbin Cros-Flow

3. Generator berkapasitas 12,5 kW, 230/389 Volt, 50/60 Hz, 3 Phase

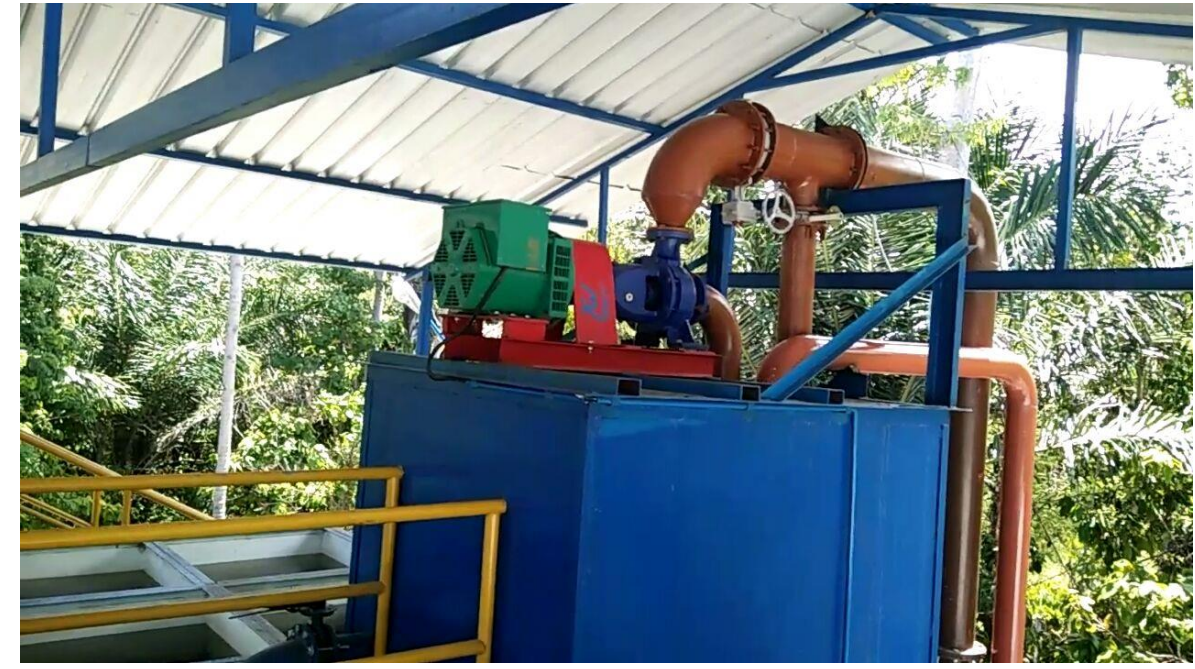

Gambar 1 Mikro hidro yang terdapat pada Instalasi Pengolahan Air (IPA) SPAM IKK Bacan 
2. Panel kontrol untuk mengatur tegangan dan mengendalikan beban listrik.

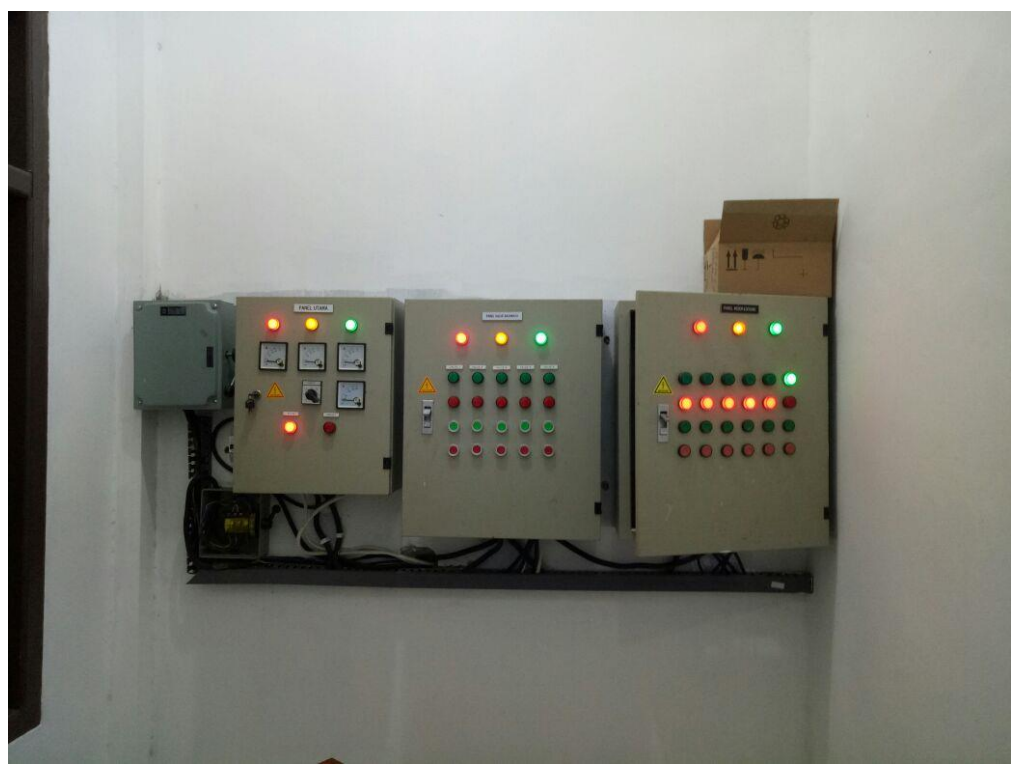

Gambar 2 Panel Kontrol yang terpasang pada mikro hidro di Instalasi Pengolahan Air (IPA) SPAM IKK

\section{Tachometer}

Tachometer berfungsi untuk mengukur putaran dari sebuah objek, khususnya jumlah putaran yang dilakukan oleh sebuah poros dalam satu satuan waktu.

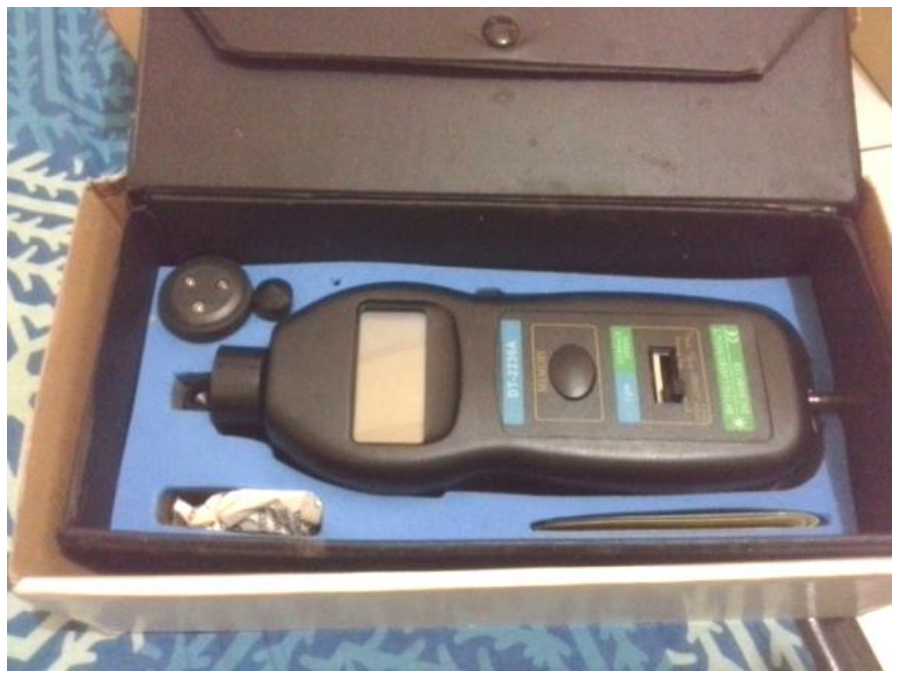

Gambar 3 alat Tachometer

\subsection{Teknik Analisis}

Jenis analisis data menggunakan pendekatan kuantitatif, dimana peneliti akan bekerja dengan angka-angka sebagai perwujudan gejala yang diamati.

\section{Tahapan Penelitian}

Adapun tahapan-tahapan penelitian yang dilaksanakan yaitu sebagai berikut:

1. Survei lokasi tempat pelaksanaan penpelitian

Survei lokasi tempat pelaksanaan penelitian dilakukan terlebih dahulu agar mempermudah proses penelitian.

2. Persiapan alat-alat yang akan digunakan 
Menyiapkan dan melengkapi alat sebelum penelitian dilakukan agar mempermudah dalam pengambilan data pada saat penelitian, alat yang digunakan antara lain:

- Tachometer untuk mengukur putaran turbin

3. Pengujian dan pengambilan data di lokasi penelitian

Data-data yang diambil yaitu meliputi data pengukuran variasi debit, daya, kapasitas dan peta/gambar jaringan instalasi pipa dari intake sampai ke mikro hidro

4. tahap analisis dan perhitungan data penelitian

Dalam tahap analisis dan perhitungan data menggunakan rumus-rumus sebagai berikut:

1. Perhitungan kecepatan aliran

$$
V=\frac{Q}{1 / 4 \cdot \pi \cdot D^{2}}(\mathrm{~m} / \mathrm{s})
$$

2. Perhitungan reynolds number

$$
R e=\frac{V \cdot D \cdot \rho}{\mu}=\frac{V \cdot D}{v}
$$

3. Perhitungan major losses

$$
H_{f}=f \frac{L \cdot V^{2}}{D \cdot 2 \cdot g} \quad(m)
$$

4. Perhitungan minor losses

$$
H_{f m}=K \frac{V^{2}}{2 \cdot g} \quad(m)
$$

5. Perhitungan total head bersih

$$
H_{\text {net }}=H_{\text {gross }}-\text { Losses }(m)
$$

6. Perhitungan daya turbin

$$
P_{t}=Q \cdot \rho \cdot g \cdot H \cdot \eta_{t} \quad(k W)
$$

7. Perhitungan daya generator

$$
P_{g}=\eta_{g} \cdot P_{t} \quad(k W)
$$

\subsection{Pembangkit Listrik Tenaga Mikro Hidro (MIKRO HIDRO)}

Mikro hidro atau yang dimaksud dengan Pembangkit Listrik Tenaga Mikro Hidro (MIKRO HIDRO) adalah suatu pembangkit listrik skala kecil yang menggunakan tenaga air sebagai tenaga penggeraknya seperti, saluran irigasi, sungai atau air terjun alam dengan cara memanfaatkan tinggi terjunan (head) dan jumlah debit air. Mikro hidro merupakan sebuah istilah yang terdiri dari kata mikro yang berarti kecil dan hidro yang berarti air.

Mikro hidro adalah Pembangkit Listrik Tenaga Air (PLTA) skala kecil dengan batasan kapasitas antara 5 kW (Kilo Watt) - 1 MW (Mega Watt) per unit (Badan Litbang ESDM, 2012). Terdapat beberapa batasan daya lain untuk kategori Mikro hidro selain yang dinyatakan oleh Badan litbang ESDM, yaitu kapasitas maksimal 120 kW dan kurang dari 200 kW (Damastuti, A.P., 1997). Ada juga penggolongan lain yang memilah sistem PLTA skala kecil menjadi tiga, yaitu Minihidro dengan kapasitas antara $100 \mathrm{~kW}$ sampai dengan $1 \mathrm{MW}$, Mikro hidro dengan kapasitas antara $1-100 \mathrm{~kW}$, dan Pikohidro dengan kapasitas dari beberapa Watt (W) sampai dengan 1000 Watt.

Beberapa komponen yang digunakan untuk Pembangkit Listrik Tenaga Mikro Hidro (MIKRO HIDRO) baik komponen utama maupun bangunan penunjang, antara lain :

1. Dam/Bendungan Pengalih (intake). Dam pengalih berfungsi untuk mengalihkan air melalui sebuah pembuka di bagian sisi sungai ke dalam sebuah bak pengendap.

2. Bak Pengendap (Settling Basin). Bak pengendap digunakan untuk memindahkan partikel-partikel pasir dari air. 
Fungsi dari bak pengendap adalah sangat penting untuk melindungi komponen-komponen berikutnya dari dampak pasir.

3. Saluran Penghantar (Headrace). Saluran pembawa mengikuti kontur dari sisi bukit untuk menjaga elevasi dari air yang disalurkan.

4. Bak Penenang (Forebay). Bak penenang berada di ujung saluran pembawa yang berfungsi untuk mecegah turbulensi air sebelum diterjunkan melalui pipa pesat.

5. Pipa Pesat (Penstock). Penstock dihubungkan pada sebuah elevasi yang lebih rendah ke sebuah roda air, dikenal sebagai sebuah turbin.

6. Turbin. Turbin berfungsi untuk mengkonversi energi aliran air menjadi energi putaran mekanis.

7. Pipa Hisap (Draft Tube). Pipa hisap berfungsi untuk menghisap air, mengembalikan tekanan aliran yang masih tinggi ke tekanan atmosfer.

8. Generator. Generator berfungsi untuk menghasilkan listrik dari putaran mekanis.

9. Panel kontrol. Panel kontrol berfungsi mengatur dan mengendalikan beban listrik yang mengunakan motor listrik sebagai penggeraknya.

10.Pengalih Beban (Ballast load). Pengalih beban berfungsi sebagai beban sekunder (dummy) ketika beban konsumen mengalami penurunan. Kinerja pengalih beban ini diatur oleh panel kontrol.

Penggunaan beberapa komponen disesuaikan dengan tempat instalasi (kondisi geografis, baik potensi aliran air serta ketinggian tempat) serta budaya masyarakat. Sehingga terdapat kemungkinan terjadi perbedaan desain MIKRO HIDRO serta komponen yang digunakan antara satu daerah dengan daerah yang lain.

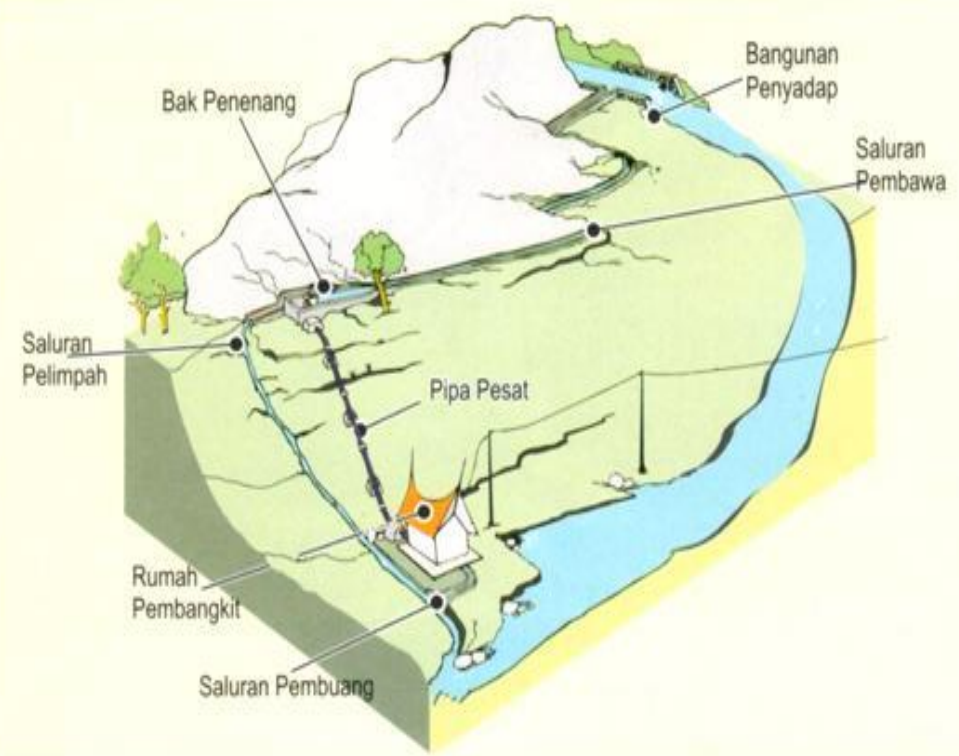

Gambar 4 Skema Pembangkit Listrik Tenaga MIkrohidro (MIKRO HIDRO).

Prinsip kerja Pembangkit Listrik Tenaga Mikro Hidro (MIKRO HIDRO) pada prinsipnya memanfaatkan beda tinggi (head) dan jumlah debit air yang ada pada aliran air saluran irigasi, sungai atau air terjun. Aliran air ini akan memutar poros turbin sehingga menghasilkan energi mekanik. Energi ini selanjutnya menggerakkan generator dan menghasilkan listrik.

Pembangunan MIKRO HIDRO perlu diawali dengan pembangunan bendungan untuk mengatur aliran air yang akan dimanfaatkan sebagai tenaga penggerak MIKRO HIDRO. Bendungan ini dapat berupa bendungan beton atau bendungan beronjong. Bendungan perlu dilengkapi dengan pintu air dan saringan sampah untuk mencegah masuknya kotoran atau endapan lumpur. Bendungan sebaiknya dibangun pada dasar sungai yang stabil dan aman terhadap banjir. 
Di dekat bendungan dibangun bangunan pengalih (intake). Kemudian dilanjutkan dengan pembuatan bak pengendap (settling basin) yang berfungsi untuk mengendapkan pasir dan menyaring kotoran sehingga air yang masuk ke turbin relatif bersih. Setelah itu dibangun saluran penghantar (headrace) yang berfungsi mengalirkan air dari intake. Saluran ini dilengkapi dengan saluran pelimpah pada setiap jarak tertentu untuk mengeluarkan air yang berlebih. Saluran ini dapat berupa saluran terbuka atau tertutup.

Bak penenang (forebay) juga dibangun untuk menenangkan aliran air dan mencegah turbulensi air sebelum diterjunkan ke pipa pesat (penstok). Saluran ini dibuat dengan konstruksi beton dan berjarak sedekat mungkin ke rumah turbin untuk menghemat pipa pesat.

Pipa pesat berfungsi mengalirkan air sebelum masuk ke turbin. Dalam pipa ini, energi potensial air di bak penenang diubah menjadi energi kinetik yang akan memutar roda turbin. Biasanya terbuat dari pipa baja yang dirol, lalu dilas. Untuk sambungan antar pipa digunakan flens. Pipa ini harus didukung oleh pondasi yang mampu menahan beban statis dan dinamisnya. Pondasi dan dudukan ini diusahakan selurus mungkin, karena itu perlu dirancang sesuai dengan kondisi tanah.

Setelah keluar dari pipa pesat, air akan memasuki turbin pada bagian inlet. Di dalamnya terdapat guided vane untuk mengatur pembukaan dan penutupan turbin serta mengatur jumlah air yang masuk ke runner blade/bilah (komponen utama turbin). Runner terbuat dari baja dengan kekuatan tarik tinggi yang dilas pada dua buah piringan sejajar. Aliran air akan memutar runner dan menghasilkan energi kinetik yang akan memutar poros turbin.

Energi yang timbul akibat putaran poros kemudian ditransmisikan ke generator. Seluruh sistem ini harus seimbang. Turbin perlu dilengkapi casing yang berfungsi mengarahkan air ke runner. Pada bagian bawah casing terdapat pengunci turbin. Bantalan (bearing) terdapat pada sebelah kiri dan kanan poros dan berfungsi untuk menyangga poros agar dapat berputar dengan lancar.

Turbin, generator dan sistem kontrol masing-masing diletakkan dalam sebuah rumah yang terpisah. Pondasi turbin-generator juga harus dipisahkan dari pondasi rumahnya. Tujuannya adalah untuk menghindari masalah akibat getaran. Rumah turbin harus dirancang sedemikian agar memudahkan perawatan dan pemeriksaan.

Pendapat pertama yang dikemukakan oleh Pudjanarsa menyatakan bahwa turbin air secara luas, sedangkan pendapat keduanya menyatakan secara spesifik tentang cara kerja turbin hidrolis, untuk pernyataan ketiga lebih spesifik dengan membagi prinsip kerja impuls dan reaksi.

\subsection{HASIL DAN PEMBAHASAN}

\subsection{Data Hasil Perhitungan}

1. Grafik pengaruh debit $(\mathrm{Q})$ terhadap daya $(\mathrm{P})$ pada data hasil perhitungan menjelaskan bahwa semakin besar debit air semakin besar pula daya yang dihasilkan. Hal ini dapat dilihat pada gambar 4.1 dimana debit $(0,01)$ $\mathrm{m} 3 / \mathrm{s}$ daya yang dihasilakan sebesar $(5,02) \mathrm{kW}$, debit $(0,0125) \mathrm{m} 3 / \mathrm{s}$ daya yang dihasilkan sebesar $(6,15) \mathrm{kW}$, debit $(0,015) \mathrm{m} 3 / \mathrm{s}$ daya yang dihasilkan sebesar $(7,19) \mathrm{kW}$, debit $(0,0175) \mathrm{m} 3 / \mathrm{s}$ daya yang dihasilkan sebesar $(8,13) \mathrm{kW}$, dan pada debit $(0,02) \mathrm{m} 3 / \mathrm{s}$ daya yang dihasilkan sebesar $(8,97) \mathrm{kW}$. 


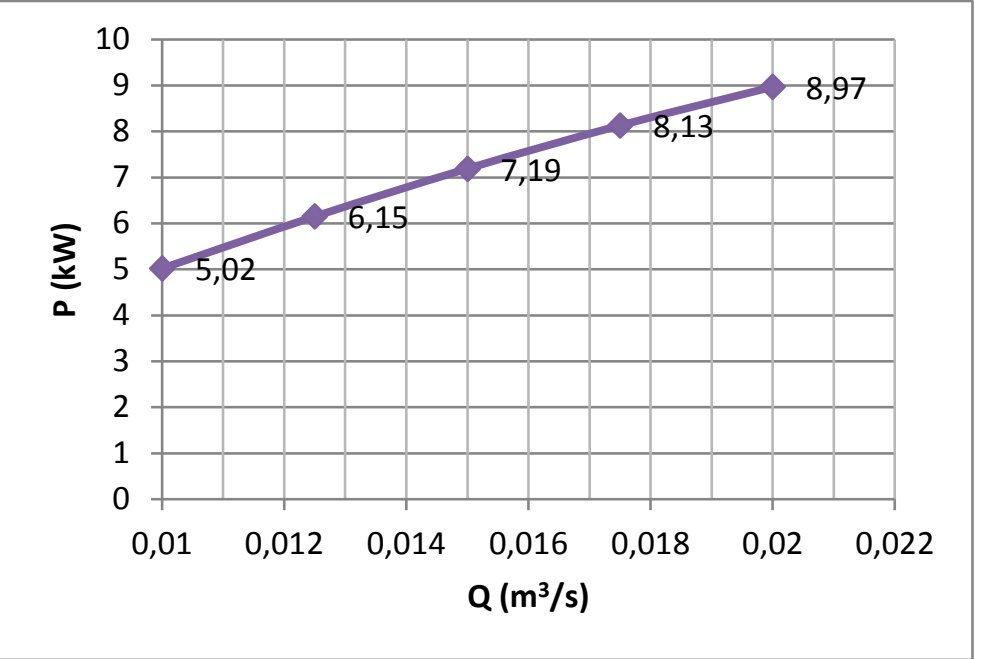

Gambar 5 Grafik pengaruh debit $(\mathrm{Q})$ terhadap daya $(\mathrm{P})$ pada data hasil perhitungan

2. Grafik pengaruh debit $(\mathrm{Q})$ terhadap daya $(\mathrm{P})$ pada data hasil penelitian menjelaskan bahwa semakin besar debit air semakin besar pula daya yang dihasilkan. Hal ini dapat dilihat pada gambar 4.2 dimana debit $(0,01) \mathrm{m}^{3} / \mathrm{s}$ daya berada pada $(4,80) \mathrm{kW}$, debit dinaikan menjadi $(0,0125) \mathrm{m}^{3} / \mathrm{s}$ daya pun naik menjadi $(5,90) \mathrm{kW}$, lalu debit dinaikan menjadi $(0,015) \mathrm{m}^{3} / \mathrm{s}$ daya pun naik menjadi $(7,08) \mathrm{kW}$, kemudian debit dinaikan lagi menjadi $(0,0175) \mathrm{m}^{3} / \mathrm{s}$ daya pun naik menjadi $(8,12) \mathrm{kW}$, samapai pada debit $(0,02) \mathrm{m}^{3} / \mathrm{s}$ daya pun naik menjadi $(8,94) \mathrm{kW}$.

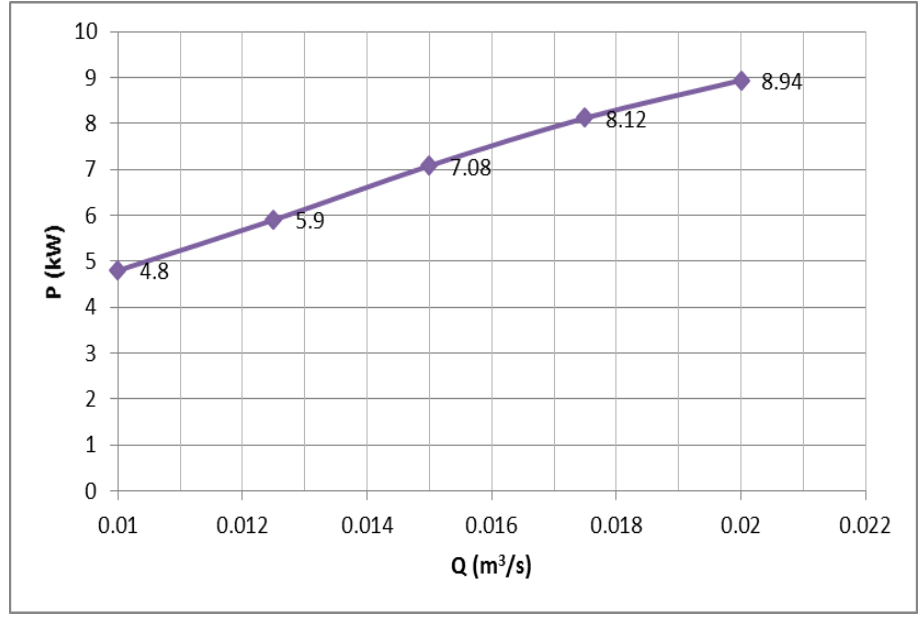

Gambar 6 Grafik pengaruh debit $(\mathrm{Q})$ terhadap daya $(\mathrm{P})$ pada data hasil perhitungan

3. Grafik pengaruh debit $(Q)$ terhadap efisiensi total $\left(\eta_{\mathrm{T}}\right)$ pada data hasil penelitian menjelaskan bahwa semakin besar debit air efisiensi total pun cenderung naik. Hal ini dapat dilihat pada gambar 4.3 dimana debit $(0,01) \mathrm{m}^{3} / \mathrm{s}$ efisiensi total $(0,727)$, debit $(0,0125) \mathrm{m}^{3} / \mathrm{s}$ efisiensi total naik menjadi $(0,729)$, debit $(0,015) \mathrm{m}^{3} / \mathrm{s}$ efisiensi total naik lagi menjadi $(0,748)$, debit $(0,0175) \mathrm{m}^{3} / \mathrm{s}$ efisiensi total naik menjadi $(0,759)$, namun pada debit $(0,02) \mathrm{m}^{3} / \mathrm{s}$ efisiensi total sedikit turun menjadi $(0,758)$. 


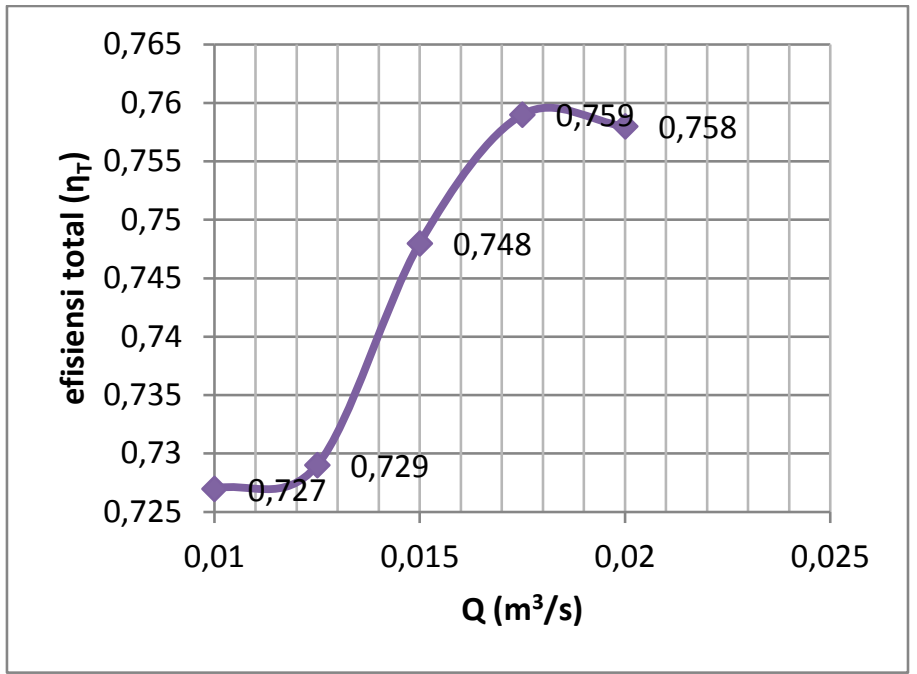

Gambar 7 Grafik pengaruh debit $(\mathrm{Q})$ terhadap efisiensi total $(\eta \mathrm{T})$ pada data hasil penelitian

\subsection{Perbandingan antara data hasil penelitian dengan data hasil perhitungan}

Grafik perbandingan pengaruh debit $(\mathrm{Q})$ terhadap daya $(\mathrm{P})$ antara data hasil penelitian dengan data hasil perhitungan dapat dilihat pada gambar 8. Dimana pada gambar tersebut menjelaskan bahwa hasil perhitungan memiliki nilai lebih tinggi dibandingkan dengan data penelitian namun tidak terlalu jauh. Angkanya dapat dilihat pada gambar 5 dan gambar 6.

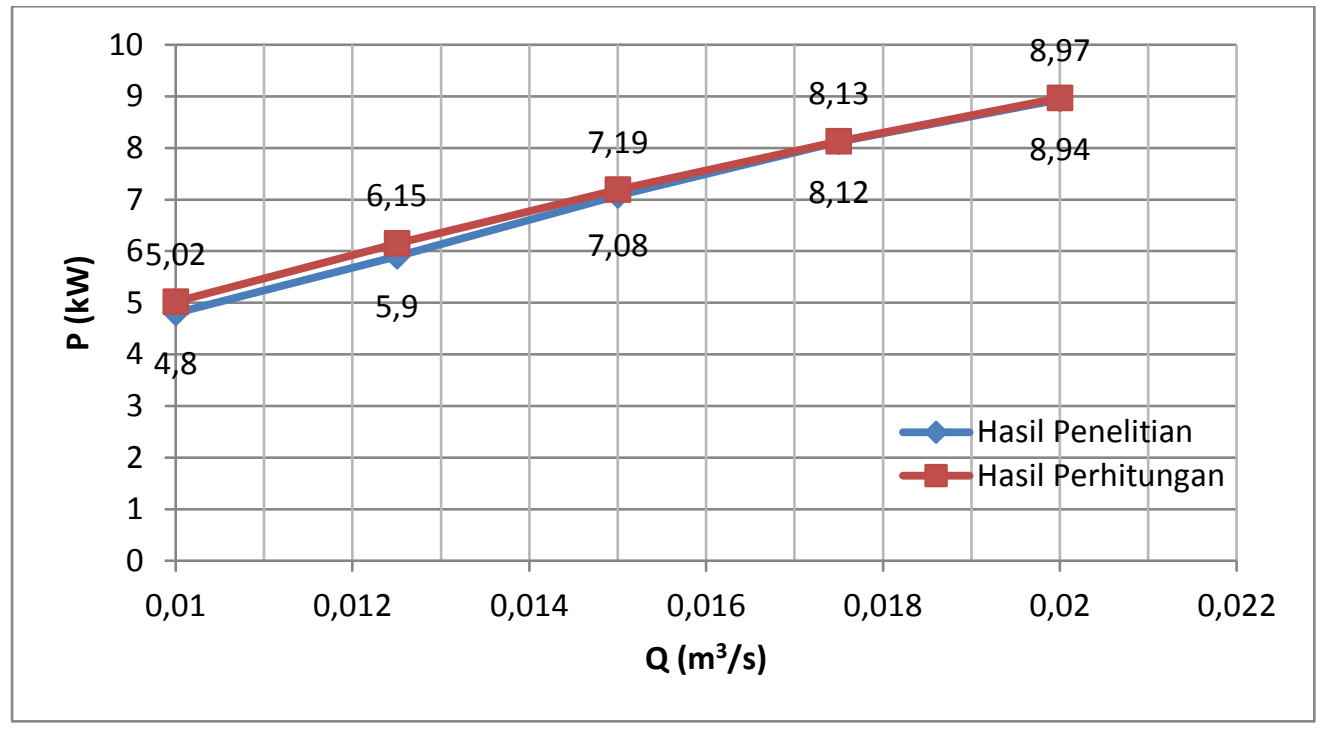

Gambar 8 Grafik perbandingan pengaruh debit (Q) terhadap daya $(\mathrm{P})$ antara data hasil penelitian dengan data hasil perhitungan

\subsection{KESIMPULAN}

Berdasarkan penelitian yang telah dilakukan dapat disimpulkan bahwa :

1. Pada data hasil perhitungan semakin besar debit air maka semakin besar pula daya yang dihasilkan. Dimana debit air $(\mathrm{Q})=(0,01-0,02) \mathrm{m}^{3} / \mathrm{s}$ menghasilakan daya keluaran generator $\left(\mathrm{P}_{\mathrm{g}}\right)$ sebesar $(5,02-8,97) \mathrm{kW}$. 
2. Pada data hasil penelitian terlihat semakin besar debit air maka semakin besar pula daya yang dihasilkan. Dimana debit air $(\mathrm{Q})=(0,01-0,02) \mathrm{m} 3 / \mathrm{s}$ menghasilkan daya keluaran generator $(\mathrm{Pg})$ sebesar $(4,80-8,94)$ $\mathrm{kW}$.

3. Pada data hasil penelitian terlihat semakin besar debit air maka semakin besar pula efisiensi total yang didapatkan. Dimana debit air $(Q)=(0,01-0,02) \mathrm{m} 3 / \mathrm{s}$, efisiensi total $(\eta \mathrm{T})$ yang didapatkan sebesar $(0,727-$ $0,759)$.

Dari ketiga penjelasan di atas maka dapat dinyatakan bahwa semakin besar debit air semakin besar pula daya keluaran dan efisiensi total yang dihasilkan. Hal ini dipengaruhi oleh head, panjang dan diameter pipa pesat, serta kecepatan aliran air. Dengan demikian perbandingan data hasil perhitungan dengan data hasil penelitian yang didapat sudah mendekati.

\section{Referensi}

Astu Pudjanarsa, Nursuhud Djati alain, Mesin Konfersi Energi. Penerbit Andi. Yogyakarta, 2006 Badan Litbang Energi dan Sumberdaya Mineral. Mikrohidro. 2012. Barlian M., Made Mara dan Yesung A.P. Perancangan Pipa Pesat, dan Daya Keluaran Pembangkit Listrik Tenaga Air Kokok Putih Desa Bilok Petung Kecamatan Sembalun Kabupaten Lombok Timur. Dinamika Teknik Mesin. 2013.Vol. 3 No. 2. Damastuti, A.P. Teknologi: Pembangkit Listrik Tenaga Mikrohidro. Wacana. Mei-Juni 1997. Vol. 8. Hunggul Y.S.H.N., M. Kudeng Sallata Mikrohidro. Penerbuit Andi. Yogyakarta, 2015. Umar K, Penuntun Praktikum Fenomena Dasar cMesin. Universitas Khairun, Ternate. PT Kusuma Wardana Group. Instalation, Operation and Maintenance of Microhydro (Radial-Flow Hydroelectric Generator). Ternate 
Halaman ini sengaja dikosongkan 